\title{
Design and Characterization of a Dual-stage, Thermally Actuated Nanopositioner
}

\author{
Neal B. Hubbard \\ hubbard_neal@yahoo.com \\ Larry L. Howell \\ lhowell@byu.edu
}

Follow this and additional works at: https://scholarsarchive.byu.edu/facpub

Part of the Mechanical Engineering Commons

\section{Original Publication Citation}

Hubbard, N.B. and Howell, L.L., Design and Characterization of a Dual-stage, Thermally Actuated Nanopositioner, Journal of Micromechanics and Microengineering, Vol. 15, pp. 1482-1493, 25.

\section{BYU ScholarsArchive Citation}

Hubbard, Neal B. and Howell, Larry L., "Design and Characterization of a Dual-stage, Thermally Actuated Nanopositioner" (2005). Faculty Publications. 354.

https://scholarsarchive.byu.edu/facpub/354 


\title{
Design and characterization of a dual-stage, thermally actuated nanopositioner
}

\author{
Neal B Hubbard and Larry L Howell \\ Department of Mechanical Engineering, Brigham Young University, 435 CTB, Provo, UT 84602, USA \\ Email: 1howell@byu.edu
}

\begin{abstract}
A nanopositioner is presented that has two stages for independent coarse and fine position control. Thermal microactuators operate both stages. The first stage includes a bistable mechanism: it travels 52 micrometers between two discrete positions. The second stage is mounted on the first stage and moves continuously through an additional 8 micrometers in the same direction as the first stage. Three approaches to the control of the second stage were evaluated in terms of accuracy and manufacturability, and one was selected for the design of the nanopositioner. The device was surface micromachined in a two-layer polysilicon process. Experiments were performed to characterize the resolution, repeatability, hysteresis, and thermal drift of the second stage of the nanopositioner with open-loop control. Position measurements were obtained from scanning electron micrographs by a numerical procedure, which is described in detail. The nanopositioner demonstrated 170-nanometer resolution and repeatability within 124 nanometers. The hysteresis of the second stage was $6 \%$ of its full range. The nanopositioner drifted 25 nanometers in the first 60 minutes of operation with a time constant of about 6 minutes. The dual-stage nanopositioner may be useful for applications such as variable optical attenuators or wavelength-specific add-drop devices.
\end{abstract}




\section{Introduction}

Nanopositioners, or nanomanipulators, control position with accuracy on the order of a few nanometers. Nanopositioners with piezoelectric actuators achieve resolution as fine as $1 \mathrm{~nm}$ $[1,2]$, and similar devices are available as commercial products. Magnetic actuators have also been utilized in nanopositioners, and resolution better than $5 \mathrm{~nm}$ has been demonstrated [3]. However, these are often desk-top-sized devices, and smaller devices are preferred for many applications. Microactuators have been proposed for a multitude of nanopositioning applications, including the control of the read/write head in a hard disk drive [4-12], tilting mirrors and gratings for directing lasers [13,14], a Fourier transform spectrometer [15], optical switches [16,17], a bar code scanner [18], a Fresnel lens [19], an atomic force microscope [20], a scanning tunneling microscope [21], fluid pumps and valves [22,23], and electrical switches [24-27]. Nanopositioners might also make it possible to assemble machines from MEMS components [28-30].

The accuracy of a position controller is the difference between the control signal it is given and the position it arrives at. Accuracy has two components: trueness and precision [31]. Trueness is a measure of the systematic uncertainty in the motion. It is constant throughout a series of repeated movements to the same position. The repeatability of a positioner is the random error in the final position when the same step input is given multiple times. Repeatability tests may be replicated with different positioners of the same design and in different locations, in which case the precision of the positioner is the Euclidean norm of the measured repeatabilities. The resolution is the smallest increment by which the position of a device can be consistently changed. Random uncertainty limits resolution by masking the distinction between the positions before and after the incremental motion. 
Table 1 summarizes the ranges, resolutions, repeatabilities, and footprints of a few microactuators. The majority of the devices listed in Table 1 have ranges on the order of $10 \mu \mathrm{m}$; the resolutions and repeatabilities are typically on the order of $10 \mathrm{~nm}$. A scratch drive actuator has a long range because it is loosely tethered to the substrate and moves its base point with each step [19]. One thermally actuated device achieves a large displacement by driving a 14-mm-long cantilever beam at resonance [18]. The resolutions and repeatabilities of thermal actuators are not generally published. However, a repeatability of $\pm 14 \mathrm{~nm}$ has been reported [33], suggesting that thermal actuators are suitable for development as micro-scale nanopositioners. Thermally actuated devices have the smallest footprints; they are typically less than $1 \mathrm{~mm}^{2}$.

In some applications, it is advantageous to control motion in multiple stages. The first stage may have a long range and move an object to approximately the desired location while the second stage achieves the necessary accuracy. The microactuators that mount on the armature of a hard disk drive [4-12] are examples of dual-stage nanopositioners. The voice coil motor moves the armature through a range of about $22 \mathrm{~mm}$ to the desired data track, and the microactuator improves the alignment of the read/write head with the track.

The objective of this paper is to introduce a dual-stage, thermal-actuator-operated nanopositioner and characterize its performance. The nanopositioner is produced by surface micromachining to take advantage of reduced size and cost. Micro-scale nanopositioners fit in tighter packages, weigh less, and use less electrical power than macro-scale nanopositioners. The nanopositioner would cost less to mass produce by surface micromachining than by macroscopic manufacturing processes such as electrical discharge machining (EDM).

The Thermomechanical In-plane Microactuator (TIM) is used in the nanopositioner design. The TIM consists of thin beams arranged in a chevron pattern around a shuttle [24]. The 
outer ends of the beams are connected to anchors that provide fixed end constraints. Figure 1a is a schematic drawing of a TIM. The heat dissipated by the electric current flowing through the beams causes them to expand, and, because of the constraints, the beams buckle (Figure 1b). The angle of the beams biases them to buckle in the intended direction. The shuttle moves along a straight path because of the symmetry of the chevron pattern.

The TIM requires less voltage than electrostatic or piezoelectric actuators, but it consumes more current and power. The voltage and current requirements of the TIM are below the limits of most power supplies. It delivers more force than a typical electrostatic actuator. The TIM is a fully compliant mechanism and thus has no revolute joints to cause backlash [38]. All of the motion is enabled by the compliance of the expansion beams. The beams suspend the shuttle above the substrate so that there is no friction to hinder precise motion. The simplicity of its monolithic design makes the TIM ideal for surface micromachining.

Two possible applications for the dual-stage nanopositioner are discussed here. First, a silica microsphere might be inserted between two optical fibers to selectively transfer specific wavelengths between them [39]. The sphere would need to be located at some distance from the fibers when no interaction was desired. When a signal was to be transferred, the sphere would need to be moved into position and carefully located in order to minimize the cross-over loss. A second application is the modulation of an optical signal with a pair of gratings [40]. Two gratings with the same period are stacked together. One is shifted relative to the other in the direction perpendicular to the slits. The fraction of the incident power that is diffracted to each order changes with the phase difference of the gratings. Conformity of the polysilicon layers in surface micromachining makes it difficult to create detailed structures in two layers at the same location. One solution might be to fabricate the gratings in different layers and at separate 
locations. The first stage of the nanopositioner could move one grating on top of the other. The power delivered to the first diffracted order could be modulated by changing the relative position of the gratings with the second stage.

The design and fabrication of the nanopositioner are discussed next. Experiments to measure the resolution, repeatability, hysteresis, and thermal drift are then described, and results are presented.

\section{Mechanical Design}

The nanopositioner is designed with two stages to achieve both a long range and good resolution. The first stage toggles between two discrete positions. The second stage moves continuously over a smaller range to adjust the final position. It has one translational degree of freedom and moves in the same direction as the first stage. The wavelength-specific add-drop device and variable optical attenuator described in Section 1 are suitable for a nanopositioner with a discrete coarse motion and a continuous fine motion.

\subsection{Coarse-Motion Stage}

Figure 2 shows the layout of the nanopositioner. A bistable mechanism [41] holds the first stage in either of its two positions in the presence of disturbance forces. The bistable mechanism requires an actuator with a long range and a high output force to move it between the two stable equilibrium positions, but it maintains its position after the actuator turns off, thus conserving power. The sliding couplers attached to the first-stage actuators allow them to retract while the first stage remains stationary (Figure 3). The couplers on the second-stage actuators enable the first stage to move freely until the second-stage actuators are energized (Figure 4). 
The Amplified Thermomechanical In-plane Microactuator (ATIM) has a set of amplifying beams between two TIMs (Figure 5). The TIMs compress the amplifying beams, and, as they buckle, the shuttle moves. An ATIM has a greater range than a TIM but provides less force. Serial arrangements of chevron-type thermal actuators, such as the ATIM, have been used for applications requiring a long range of motion [34,36,37,42-44]. Two ATIMs pull the coarsemotion stage of the nanopositioner from the as-fabricated position to the second position; another pair of ATIMs moves it in the reverse direction. Figure 6 is a scanning electron micrograph of one half of one ATIM.

The bistable mechanism has two beams, one on each side of the shuttle, that buckle as the shuttle is displaced (Figure 7). Each buckling beam consists of a stiff segment between two flexible segments. The flexures at the ends of the buckling beams soften the constraints and relieve stress. The bistable mechanism contacts a stiff block before it reaches its second stable equilibrium position. The block gives it a repeatable stopping place. The coarse displacement is set to $52 \mu \mathrm{m}$ in the design.

\subsection{Fine-Motion Stage}

Independent operation of the first and second stages requires two independent inputs. The coarse-motion stage receives electric current through traces and wires attached to the chip. The input for the fine-motion stage may be electrical, optical, or mechanical. In this section, these three possibilities are evaluated in terms of accuracy and the ease of implementation.

In the case of electrical input, the first stage consists of two sections that have different electrical potentials. The TIM that actuates the second stage spans the gap between the sections and forms the only path for current to flow from one section to the other. The current may be delivered to the TIM through electrical contacts or the beams of the bistable mechanism. 
Dividing the first stage into two sections means providing separate ATIMs for each section; the result is a large footprint. In order for the second stage to work, the TIM must be tightly constrained in the transverse direction. When it is actuated, it pushes outward on the sections of the first stage and must be resisted in order to generate a useful displacement in the intended direction. If a mechanical link between the two sections of the first stage were made of polysilicon, it would draw current away from the TIM. It would also heat up and expand, making it ineffective as a displacement constraint. An insulating material, such as hardened photoresist, may be used to link components with different electrical potentials [19]. Another option is to place restraint blocks beside the first stage; the TIM would expand until it contacted the blocks, then the constraint would cause it to buckle as intended. The necessary gaps between the first stage and the restraint blocks would reduce the range of the TIM and introduce random uncertainty in its motion. The concept of supplying an electrical input to an actuator mounted on the first stage was investigated but was rejected because of the difficulty of providing a suitable constraint [45].

Electrical control is the simplest to implement with MEMS, but other power sources are available. A novel approach to heating a thermal actuator is to illuminate it with an infrared laser [36]. The intensity of the laser may be attenuated for precise control of the actuator. The difficulty of this approach is in packaging. A laser emitter is required in addition to an electronic power supply, and proper alignment of the laser and actuator are imperative.

Mechanical transmission was selected as the means of controlling the second stage of the nanopositioner. The TIM was chosen for the second-stage actuators; there is one on either side of the first stage (Figure 2). The ATIMs move the first stage into position between the two TIMs so that the shuttles of the TIMs align with contact points on the first stage. Small $(0.4 \mu \mathrm{m})$ gaps 
between the TIMs and the first stage facilitate the coarse motion. The TIMs close the gaps and deflect the first stage. An amplifier mechanism mounted on the first stage converts the displacement of the TIMs to the same direction as the coarse motion and increases its magnitude. The first stage has flexible members that provide stiff support for the amplifier mechanism in the direction of the coarse motion yet minimal resistance to the action of the TIMs. Figure 8 shows the second stage integrated with the first stage.

The advantage of the mechanical control concept is that the second-stage actuators are mounted on the substrate, which provides the necessary constraint as well as a direct electrical connection. The disadvantage is that there must be gaps between the TIMs and the first stage in order for the first stage to move. The bistable mechanism holds the first stage against the stop block in its second position so that the TIMs grip it in the same place each time they actuate. However, the gaps remain a source of random position error. The rough edges of the mating parts mesh differently each time, and the surfaces change with wear. The random error due to gap closure may be eliminated during operation by maintaining enough current in the TIMs to keep the gaps closed.

Figure 9 is a scanning electron micrograph of the entire nanopositioner, illustrating the components of the first and second stages. The footprint is $3.431 \mathrm{~mm} \times 1.632 \mathrm{~mm}$. As was mentioned previously, a pair of gratings may be used to control the intensities of the diffracted orders of a laser. To demonstrate the possibility, a moveable grating is attached to the second stage and a non-moving grating is created next to it in a different layer (Figure 9f). The first stage places the moveable grating directly above the fixed grating (Figure $8 b$ ), and the second stage moves the upper grating through a displacement greater than the period of the gratings. 


\section{Fabrication}

The nanopositioner was fabricated by surface micromachining through the Multi-User MEMS Processes (MUMPs) [46]. An insulating layer of silicon nitride on a silicon wafer forms the substrate. The first layer of polysilicon is $500 \mathrm{~nm}$ thick and serves as a conductive background for scanning electron microscopy. The polysilicon covers the silicon nitride in the regions where high-resolution images need to be obtained. It is electrically connected to the microscope stage, so it provides a ground path for the electron beam. Without it, electrical charge would accumulate in the silicon nitride and deflect the electron beam, reducing image quality.

The two releasable polysilicon layers are $2.0 \mu \mathrm{m}$ and $1.5 \mu \mathrm{m}$ thick. They were each annealed at $1050{ }^{\circ} \mathrm{C}$ for 1 hour to dope the polysilicon with phosphorus and relieve internal stress. A 500-nm-thick layer of gold was deposited and patterned on the top layer of polysilicon to form electrical traces.

The mechanisms were released by wet etching the sacrificial oxide in hydrofluoric acid for $170 \mathrm{~s}$. The water was removed by rinsing the chip in isopropyl alcohol and placing it in a dryer at $110^{\circ} \mathrm{C}$ for 15 minutes. The drying process was not ideal: it did little to prevent the mechanisms from adhering to the substrate. Stiction was observed during testing.

\section{Characterization}

The first stage of the nanopositioner required $159 \mathrm{~mA}$ at $7.6 \mathrm{~V}$, or $1.21 \mathrm{~W}$, to move from the first position to the second and $141 \mathrm{~mA}$ at $6.6 \mathrm{~V}$, or $0.93 \mathrm{~W}$, to return to the first position. The range of the first stage was $52 \mu \mathrm{m}$. The second stage traveled an additional $8 \mu \mathrm{m}$, extending the total range to $60 \mu \mathrm{m}$.

The resolution, repeatability, hysteresis, and thermal drift of the second stage were determined experimentally. The tests were performed with open-loop current control. The digital 
current source had a resolution of $0.1 \mathrm{~mA}$ and maintained the current setting within $10 \mu \mathrm{A}$ throughout the tests. Position measurements were obtained from images acquired with a scanning electron microscope (SEM) after the nanopositioner had reached a steady-state displacement. The SEM images were taken with a magnification of 5000 times, an accelerating potential of $5 \mathrm{kV}$, a working distance of $20 \mathrm{~mm}$, and a spot size of 3 on a scale from 1 to 7,1 being the smallest. Unlike the first stage, which was tested in air, the second stage was tested in the SEM chamber under high vacuum. An electrical interface on the SEM enabled the nanopositioner to connect to an external power supply. Thermal actuators require less power to reach a given displacement in vacuum than in air [27], so the first stage would operate with less power in the SEM.

The procedure for obtaining position measurements from scanning electron micrographs is explained in the following section. The experiments that were conducted to characterize the accuracy of the nanopositioner are described with the results in subsequent sections.

\subsection{Measurement Process}

Figure 10 shows a portion of the second stage of the nanopositioner. The ruler anchored to the substrate near the second stage served as a reference for position measurements. The images acquired by the SEM were analyzed numerically to measure the position of the moving object (the second stage) relative to the reference object (the ruler). The numerical procedure made it possible to measure the images consistently. Figure 11a is a single image from one of the repeatability tests. The finger on the second stage and a few fingers of the ruler are visible. The image was first cropped to a convenient size that included straight portions of both the moving and reference objects. In Figure $11 \mathrm{~b}$, the moving object is on the left, and the reference object is on the right. The edges of the objects were aligned with the columns of the image. The grayscale 
values of the pixels in each column of Figure 11b were averaged. The column averages are plotted in Figure 12 on a scale from 0 (black) to 1 (white).

The edges of the moving and reference objects appear as steep slopes in Figure 12. The edges were identified by investigating the derivative of the grayscale value with respect to the column number (Figure 13). The derivative was computed with a second-order central difference equation. The edge of the moving object is selected as an example to illustrate the method of locating an object. Figure 11c is an enlarged view of a few pixels near the edge of the moving object. The edge is characterized by a gradual shift from dark to light. The grayscale profile of the edge is Figure 14, and the derivative is Figure 15. A threshold value of the derivative (0.015 pixel $^{-1}$ in this example) was chosen. Pixels for which the derivative was greater than the threshold were identified as belonging to the edge.

A linear fit equation for the pixels on the edge of the moving object was computed by the least squares method (Figure 14). The equation for the grayscale value $g$ at column number $s$ is

$$
g=m s+c
$$

with coefficients $m$ and $c$. A benchmark grayscale value was chosen at approximately the mean grayscale value of the pixels that belonged to the edge. The location of the moving object $\left(s_{m}\right)$ relative to the left side of the image was defined as the intersection of the linear fit equation (Equation 1) and the benchmark (b):

$$
s_{m}=\frac{b-c}{m}
$$

In this example, $m=5.065 \times 10^{-2}$ pixel $^{-1}, c=-4.589, b=0.55$, and $s_{m}$ evaluated to 101.5 pixels.

The reference object was located in the same manner as the moving object. The relative position of the second stage was 


$$
p=\frac{s_{m}-s_{r}}{f}
$$

where $s_{r}$ was the location of the reference object and $f$ was a calibration factor relating the image unit (pixel) to a standard unit (micrometer). For the image in Figure 11b, $s_{r}=606.4$ pixels, $f=$ 52.84 pixels $\mu \mathrm{m}^{-1}$, and $p=-9.557 \mu \mathrm{m}$. The displacement of the second stage was the difference between the measured position and the average position with no current flowing through the TIMs.

The repeatability of the measurement process was determined by measuring the distance between two fingers on the ruler adjacent to the nanopositioner. Four tests were performed on two different days; features with nominal dimensions of $6 \mu \mathrm{m}$ and $12 \mu \mathrm{m}$ were measured on each day. The $95 \%$ precision intervals of the four tests are given in Table 2 . The mean values do not exactly equal the nominal dimensions partly because the ruler was not fabricated exactly as designed. The precision of the measurement process is the Euclidean norm of the four repeatability measurements. It evaluates to $\pm 6.1 \mathrm{~nm}$, which is equivalent to \pm 0.32 pixels.

Processes that occur over long periods of time, such as the accumulation of electrostatic charge, may cause position measurements to drift. The stability of the measurement process was tested by measuring the ruler repeatedly over a period of 72 minutes. The maximum deviation from the initial measurement was $3.5 \mathrm{~nm}$, so the measurement process was sufficiently stable for the nanopositioner characterization tests. The nanopositioner was actuated during both the repeatability and stability tests; therefore, the actuation voltage is not detrimental to the SEM measurements. For more detail regarding the calibration and qualification of the measurement process, refer to [45]. 


\subsection{Resolution}

The objective of a resolution test is to measure the smallest step that can be distinguished in the motion of a nanopositioner. The input is increased by steps, and the position is measured 10 times at each step. The position at each step is the mean of the 10 measurements. The $95 \%$ precision interval about the mean quantifies the total uncertainty in the position, which is a composite of the uncertainties in the measurement and in the motion of the device. The size of each step is the difference between its mean position and that of the previous step. A step is considered to be resolved if the precision interval of that step does not overlap the precision interval of the previous step. The resolution measured in a single test is the average size of the steps that are resolved. The resolution of a nanopositioner is the smallest resolution measured in any test. Random uncertainty limits resolution because if the precision intervals of two positions overlap, the measurements are not distinct, and it is not possible to predict with the assumed probability that the input will result in one position and not the other.

Two tests were performed to measure the resolution of the second stage; both began at a displacement greater than half of the range. In the first resolution test, the nominal current increment was $0.1 \mathrm{~mA}$. The measured values of the current, voltage, and power for each step are listed in Table 3. The uncertainties in the average values of the current, voltage, and power are $\pm 0.002 \mathrm{~mA}, \pm 0.0002 \mathrm{~V}$, and $\pm 0.006 \mathrm{~mW}$, respectively, for both resolution tests. Figure $16 \mathrm{a}$ shows the results of the first test; the mean displacement for each step is marked with a solid line, and the precision interval is delimited with dashed lines. The nanopositioner was not able to resolve steps of this size. It did not always move when the input changed, and the step sizes were not consistent. 
The nominal current increment in the second resolution test was $0.2 \mathrm{~mA}$. The electrical inputs are summarized in Table 4, and the measurements are plotted in Figure 16b. The nanopositioner exhibited stick-slip behavior at step 3, indicating that the second stage contacted the substrate. The abrupt movement after the third measurement increased the width of the precision interval. The displacement at step 4 was slightly less than the displacement in the last 7 measurements at step 3; the nanopositioner did move in reverse, but it did not move beyond the precision interval of step 3, so step 4 was not resolved. The nanopositioner clearly resolved steps 2, 3, and 5. The sizes of these steps were $142 \mathrm{~nm}, 236 \mathrm{~nm}$, and $132 \mathrm{~nm}$, respectively. The resolution of the nanopositioner was $170 \mathrm{~nm}$.

Table 5 summarizes the experimental results for the second stage of the nanopositioner. The displacement, current, and voltage listed with each test are measured data that represent the test conditions; they are the average values for the first steps of the resolution tests, the average values for the repeatability tests, the maximum values for the hysteresis tests, and the initial values in the thermal drift test.

\subsection{Repeatability}

Repeatability is the random error observed during a series of attempts to move to the same position from the same direction. The random error is quantified by a precision interval based on the Student's $t$ distribution [31]. The precision interval was defined at a probability of $95 \%$.

There were 29 measurements taken in the first repeatability test. The current was cycled from $0 \mathrm{~mA}$ to $29.58 \mathrm{~mA}$ for each repetition. The average voltage and power were $2.501 \mathrm{~V}$ and $74.0 \mathrm{~mW}$, respectively. The uncertainties in the average electrical inputs were $\pm 0.0009 \mathrm{~mA}$, $\pm 0.00009 \mathrm{~V}$, and $\pm 0.003 \mathrm{~mW}$ for the repeatability tests. Figure $17 \mathrm{a}$ presents the distribution of the displacement. The mean displacement was $4.550 \mu \mathrm{m}$, and the repeatability was $\pm 124 \mathrm{~nm}$. 
The second repeatability test consisted of 31 measurements. Unlike the first test, the nanopositioner was not turned off before each repetition. The current was cycled between 17.71 $\mathrm{mA}$ and $26.61 \mathrm{~mA}$, so the TIMs did not lose contact with the sliding frame of the first stage. The mean displacements at the low and high current levels were $0.603 \mu \mathrm{m}$ and $3.691 \mu \mathrm{m}$, respectively; the net displacement was $3.088 \mu \mathrm{m}$. The average voltage was $2.186 \mathrm{~V}$ and the power was $58.2 \mathrm{~mW}$ at the high current level. The distribution of the displacement at the high current level is shown in Figure 17b. By eliminating the random error associated with gripping and releasing the first stage, the repeatability was improved to $\pm 37 \mathrm{~nm}$.

\subsection{Hysteresis}

The hysteresis is the error involved in approaching a position from opposite directions. Coulomb friction is the primary cause of hysteresis. A hysteresis test involves incrementing the input from zero to the safe operating limit and back. The inputs for the downscale motion must be identical to those of the upscale motion. The hysteresis at each level is

$$
h=\left|p_{r}-p_{f}\right|
$$

where $p_{f}$ and $p_{r}$ are the positions measured in the forward and reverse directions, respectively. Let the largest hysteresis observed over the course of the test be $h_{\max }$, and let the maximum displacement be $d_{\max }$. The hysteresis of the nanopositioner is expressed as a fraction of the range:

$$
H=\frac{h_{\max }}{d_{\max }} \cdot 100 \%
$$

Two hysteresis tests were performed with the nanopositioner. In the first test, the current was stepped from $0 \mathrm{~mA}$ to $33.5 \mathrm{~mA}$ and back to $0 \mathrm{~mA}$ in increments of $3.35 \mathrm{~mA}$. The displacements measured at each step are plotted in Figure 18. The nanopositioner required about $16 \mathrm{~mA}$ to close the gaps between the TIMs and the first stage. After making contact, the TIMs 
compressed the amplifying mechanism, and the second stage moved. The maximum displacement was $8.5 \mu \mathrm{m}$ and required $2.919 \mathrm{~V}$ and $97.8 \mathrm{~mW}$ of power. For both hysteresis tests, the uncertainties in the current, voltage, and power were $\pm 0.05 \mathrm{~mA}, \pm 0.0005 \mathrm{~V}$, and $\pm 0.1 \mathrm{~mW}$, respectively. The largest hysteresis was $560 \mathrm{~nm}$, or $6.6 \%$ of the full range. The displacements measured when the device was moving in the reverse direction were all greater than the forward measurements made at the same steps. Friction opposes motion, so it is probably the cause of the hysteresis.

In the second test, the current began at $15.78 \mathrm{~mA}$ and increased by increments of $1.77 \mathrm{~mA}$ up to $33.5 \mathrm{~mA}$; then it decreased by the same increments back to $15.78 \mathrm{~mA}$. The gaps were closed on the first step, so the other steps all had positive displacements (Figure 18). The nanopositioner achieved a maximum displacement of $8.6 \mu \mathrm{m}$ with $2.918 \mathrm{~V}$ and $97.8 \mathrm{~mW}$ of power. The hysteresis was $477 \mathrm{~nm}$, or $5.5 \%$ of the full range.

\subsection{Drift}

Drift is a measure of the stability of a nanopositioner over time. It may be caused by transient heat transfer with a large time constant. It is measured by applying a step input to the nanopositioner and measuring the position after some time. The absolute drift of the nanopositioner at a particular time is given by

$$
D=p-p_{1}
$$

where $p$ is the instantaneous position and $p_{1}$ is the position at the beginning of the test.

Position errors are expected to be greatest when the displacement is large, so the error measured near the displacement limit may be assumed to be an upper bound for the entire range of motion. The thermal drift was expected to be small, so the test was performed near the limit of the range, at a displacement of $6.965 \mu \mathrm{m}$. The measured current was $32.50 \pm 0.005 \mathrm{~mA}$, and the 
voltage was $2.800 \pm 0.0005 \mathrm{~V}$. Time zero corresponded to the beginning of the first SEM scan. The first five measurements were taken at intervals of $75 \mathrm{~s}$. Subsequent measurements were taken at 10 minutes from the first image and every 10 minutes thereafter, up to a total time of 60 minutes. The thermal drift is plotted against time in Figure 19. The second stage drifted $25 \mathrm{~nm}$ over the course of the test. By fitting a negative exponential curve to the data, the time constant was estimated to be about 6 minutes.

The test reported above demonstrates that the drift due to transient heat transfer is small. Additional tests would be needed in order to completely characterize the temporal behavior of the nanopositioner. Physical changes occur in polysilicon over long time intervals and after large numbers of cycles that affect the performance of thermal actuators. The position reached by a thermal actuator with constant input power has been shown to increase by $2 \mu \mathrm{m}(22 \%)$ over 500 minutes [47]. The displacement of a thermal actuator can increase by more than $25 \%$ after 30 million cycles [48]. These changes have been linked to annealing of the polysilicon. In order to develop the nanopositioner as a commercial product, reliability would have to be tested and improved. Reliability testing is beyond the scope of this paper.

The feedback control of a thermal actuator has been demonstrated with an on-chip piezoresistive sensor $[49,50]$. If implemented, feedback control could significantly improve the performance of the nanopositioner. It has the potential to improve repeatability, reduce hysteresis, and compensate for position errors that develop over long periods of time.

\section{Conclusion}

A nanopositioner with two stages was designed and fabricated by surface micromachining. Both stages control the same translational degree of freedom. A large thermal actuator moves the first stage $52 \mu \mathrm{m}$ and a bistable mechanism holds it in position. Smaller thermal actuators move the 
second stage an additional $8 \mu \mathrm{m}$ with greater accuracy than could be achieved with the large actuator. The motion of the second-stage actuators is transmitted to the second stage by a compliant mechanism integrated in the first stage.

The novelty of the proposed nanopositioner is that both the coarse- and fine-motion stages are integrated on a single silicon chip. Microactuators have been employed for the second stages of some dual-stage nanopositioners [4-12], but in each of these cases the first stage is a macro-scale device. The dual-stage nanopositioner has the potential to exceed the ranges of single-stage nanopositioners. It could possibly produce greater forces than other micro-scale nanopositioners because it is driven by thermal actuators.

Experiments were performed to quantify the resolution, repeatability, hysteresis, and thermal drift of the nanopositioner. Position measurements were made with a scanning electron microscope. The nanopositioner moved with reasonable accuracy under open-loop control and demonstrated the feasibility of thermal actuators for on-chip, dual-stage nanopositioners. Improvements may be made in the design and fabrication to increase stiffness and reduce friction. Greater stiffness would make the nanopositioner less sensitive to mechanical disturbances and so that it would achieve better resolution.

\section{Acknowledgements}

The authors wish to thank Michael Standing for assistance with the SEM and Robert Messenger for guidance in measuring position from SEM images. 


\section{References}

[1] Ku S-S, Pinsopon U, Cetinkunt S and Nakajima S 2000 Design, fabrication, and real-time neural network control of a three-degrees-of-freedom nanopositioner IEEE/ASME Trans. Mechatron. 5 273-280

[2] Scire F E and Teague E C 1978 Piezodriven 50- $\mu \mathrm{m}$ range stage with subnanometer resolution Rev. Sci. Instrum. 49 1735-1740

[3] Culpepper M L and Anderson G 2004 Design of a low-cost nano-manipulator which utilizes a monolithic, spatial compliant mechanism Precis. Eng. 28 469-482

[4] Cheung P, Horowitz R and Howe R T 1996 Design, fabrication, position sensing, and control of an electrostatically-driven polysilicon microactuator IEEE Trans. Magn. 32 122-128

[5] Hirano T, Fan L-S, Lee W Y, Hong J, Imaino W, Pattanaik S, Chan S, Webb P, Horowitz R, Aggarwal S and Horsley D A 1998 High-bandwidth high-accuracy rotary microactuators for magnetic hard disk drive tracking servos IEEE/ASME Trans. Mechatron. 3 156-165

[6] Hirano T, Fan L-S, Semba T, Lee W Y, Hong J, Pattanaik S, Webb P, Juan W-H and Chan S 1999 High-bandwidth HDD tracking servo by a moving-slider micro-actuator IEEE Trans. Magn. 35 3670-3672

[7] Horsley D A, Wongkomet N, Horowitz R and Pisano A P 1999 Precision positioning using a microfabricated electrostatic actuator IEEE Trans. Magn. 35 993-999

[8] Imamura T, Katayama M, Ikegawa Y, Ohwe T, Koishi R and Koshikawa T 1998 MEMSbased integrated head/actuator/slider for hard disk drives IEEE/ASME Trans. Mechatron. 3 $166-174$

[9] Kim B-H and Chun K 2001 Fabrication of an electrostatic track-following micro actuator for hard disk drives using SOI wafer J. Micromech. Microeng. 11 1-6

[10] Soeno Y, Ichikawa S, Tsuna T, Sato Y and Sato I 1999 Piezoelectric piggy-back microactuator for hard disk drive IEEE Trans. Magn. 35 983-987

[11] Toshiyoshi H, Mita M and Fujita H 2002 A MEMS piggyback actuator for hard-disk drives J. Microelectromech. Syst. 11 648-654

[12] Wang Z H, Zhu W G and Yao X 2002 d(31) type inplane bending multilayer piezoelectric microactuators-A design concept and its applications Sens. Actuators A Phys. 101262 268 
[13] Hoen S, Bai Q, Harley J A, Horsley D A, Matta F, Verhoeven T, Williams J and Williams K R 2003 A high-performance dipole surface drive for large travel and force Proc. Int. Conf. Solid State Sensors Actuators 1 344-347

[14] Reid P R, Bright V M and Comtois J H 1996 Force measurements of polysilicon thermal microactuators Proc. SPIE 2882 296-306

[15] Manzardo O, Herzig H P, Marxer C R and de Rooij N F 1999 Miniaturized time-scanning Fourier transform spectrometer based on silicon technology Opt. Lett. 24 1705-1707

[16] Jang W I, Choi C A, Lee M L, Jun C H and Kim Y T 2002 Fabrication of MEMS devices by using anhydrous HF gas-phase etching with alcoholic vapor J. Micromech. Microeng. 12 297-306

[17] Shen S-C, Pan C-T and Chou H-P 2002 Electromagnetic optical switch for optical network communication J. Magn. Magn. Mater. 239 610-613

[18] Syms R R A 2002 Long-travel electrothermally driven resonant cantilever microactuators $J$. Micromech. Microeng. 12 211-218

[19] Fan L, Wu M C, Choquette K D and Crawford M H 1997 Self-assembled microactuated XYZ stages for optical scanning and alignment Proc. Int. Conf. Solid State Sensors Actuators 1 319-322

[20] Jaecklin V P, Linder C, de Rooij N F and Moret J-M 1993 Comb actuators for XYmicrostages Sens. Actuators A Phys. 39 83-89

[21] Xu Y, Miller S A and MacDonald N C 1995 Microelectromechanical scanning tunneling microscope Proc. Int. Conf. Solid State Sensors Actuators 1 640-643

[22] Neagu C R, Gardeniers J G E, Elwenspoek M and Kelly J J 1996 An electrochemical microactuator: Principle and first results J. Microelectromech. Syst. 5 2-9

[23] Neagu C R, Gardeniers J G E, Elwenspoek M and Kelly J J 1997 An electrochemical active valve Electrochim. Acta 42 3367-3373

[24] Cragun R and Howell L L 1999 Linear thermomechanical microactuators Proc. ASME Micro Electro Mech. Syst. 181-188

[25] Guckel H, Klein J, Christenson T, Skrobis K, Laudon M and Lovell E G 1992 Thermomagnetic metal flexure actuators Technical Digest-IEEE Solid-State Sensor Actuator Workshop 73-75

[26] Li J, Brenner M P, Lang J H, Slocum A H and Struempler R 2003 DRIE-fabricated curvedelectrode zipping actuators with low pull-in voltage Proc. Int. Conf. Solid State Sensors Actuators 1 480-483 
[27] Lott C D, McLain T W, Harb J N and Howell L L 2002 Modeling the thermal behavior of a surface-micromachined linear-displacement thermomechanical microactuator Sens.

Actuators A Phys. $101239-250$

[28] Fukuta Y, Collard D, Akiyama T, Yang E H and Fujita H 1997 Microactuated self-assembling of 3D polysilicon structures with reshaping technology Proc. IEEE Micro Electro Mech. Syst. 477-481

[29] Jonsmann J, Sigmund O and Bouwstra S 1999 Compliant electro-thermal microactuators Proc. IEEE Micro Electro Mech. Syst. 588-593

[30] Sun Y, Piyabongkarn D, Sezen A, Nelson B J and Rajamani R 2002 A high-aspect-ratio two-axis electrostatic microactuator with extended travel range Sens. Actuators A Phys. 102 $49-60$

[31] Figliola R S and Beasley D E 2000 Theory and Design for Mechanical Measurements 3rd edn (New York: John Wiley \& Sons) 15-21,121-122

[32] Jaecklin V P, Linder C, de Rooij N F and Moret J-M 1992 Micromechanical comb actuators with low driving voltage J. Micromech. Microeng. 2 250-255

[33] Hubbard N B and Howell L L 2004 Experimental repeatability of a thermal actuator for nanopositioning Proc. ASME Micro Electro Mech. Syst. IMECE2004-59616

[34] Park J-S Chu L L Oliver A D and Gianchandani Y B 2001 Bent-beam electrothermal actuators-Part II: Linear and rotary microengines J. Microelectromech. Syst. 10 255-262

[35] Comtois J H, Michalicek M A and Barron C C 1997 Characterization of electrothermal actuators and arrays fabricated in a four-level, planarized surface-micromachined polycrystalline silicon process Proc. Int. Conf. Solid State Sensors Actuators 2 769-772

[36] Oliver A D Vigil S R and Gianchandani Y B 2003 Photothermal surface-micromachined actuators IEEE Trans. Electron Devices 50 1156-1157

[37] Que L Park J-S and Gianchandani Y B 2001 Bent-beam electrothermal actuators-Part I: Single beam and cascaded devices J. Microelectromech. Syst. 10 247-254

[38] Howell L L 2001 Compliant Mechanisms (New York: John Wiley \& Sons) 3

[39] Cai M, Hunziker G and Vahala K 1999 Fiber-optic add-drop device based on a silica microsphere-whispering gallery mode system IEEE Photonics Technol. Lett. 11 686-687

[40] Sene D E, Bright V M, Comtois J H and Grantham J W 1996 Polysilicon micromechanical gratings for optical modulation Sens. Actuators A Phys. 57 145-151 
[41] Jensen B D, Parkinson M B, Kurabayashi K, Howell L L and Baker M S 2001 Design optimization of a fully-compliant bistable micro-mechanism Proc. ASME Micro Electro Mech. Syst. 3 357-363

[42] Baker M S 2002 On-chip Actuation of Compliant Bistable Micro-mechanisms MS Thesis Brigham Young University, Provo, UT 34-35

[43] Gomm T, Howell L L and Selfridge R H 2002 In-plane linear-displacement bistable microrelay J. Micromech. Microeng. 12 257-264

[44] Jensen K A and Howell L L 2003 An XZ micropositioning mechanism (XZMM) with outof-plane translation Proc. ASME Des. Eng. Tech. Conf. 2B 1185-1190

[45] Hubbard N B 2005 Dual-stage thermally actuated surface-micromachined nanopositioners MS Thesis Brigham Young University, Provo, UT

[46] Koester D, Cowen A, Mahadevan R, Stonefield M and Hardy B 2003 PolyMUMPs Design Handbook Revision 10.0 (San Jose, CA: MEMSCAP)

[47] Que L, Otradovec L, Oliver A D and Gianchandani Y B 2001 Pulse and DC operation lifetimes of bent-beam electrothermal actuators Proc. IEEE Micro Electro Mech. Syst. 570573

[48] Chu L L, Nelson D, Oliver A D and Gianchandani Y B 2003 Performance enhancement of polysilicon electrothermal microactuators by localized self-annealing Proc. IEEE Micro Electro Mech. Syst. 68-71

[49] Messenger R K 2004 Modeling and control of surface micromachined thermal actuators $M S$ Thesis Brigham Young University, Provo, UT

[50] Messenger R K, McLain T W and Howell L L 2004 Feedback control of a thermomechanical inplane microactuator using piezoresistive displacement sensing Proc. ASME Micro Electro Mech. Syst. IMECE2004-59810 
Table 1. Characteristics of Selected Microactuators

\begin{tabular}{|c|c|c|c|c|c|}
\hline Source & Type & Range & Resolution & Repeatability & Footprint \\
\hline Hoen et al., 2003 [13] & Electrostatic & $50 \mu \mathrm{m}$ & $1.5 \mathrm{~nm}$ & $\pm 4 \mathrm{~nm}$ & $3.0 \mathrm{~mm} \times 2.5 \mathrm{~mm}$ \\
\hline Horsley et al., 1999 [7] & Electrostatic & $2.8 \mu \mathrm{m}$ & - & $\pm 2 \mathrm{~nm}$ & $2.0 \mathrm{~mm} \times 2.2 \mathrm{~mm}$ \\
\hline Manzardo et al., 1999 [15] & Electrostatic & $77 \mu \mathrm{m}$ & - & $\pm 25 \mathrm{~nm}$ & $5 \mathrm{~mm} \times 4 \mathrm{~mm}$ \\
\hline Fan et al., 1997 [19] & Electrostatic & $250 \mu \mathrm{m}$ & $27 \mathrm{~nm}$ & - & $1.6 \mathrm{~mm} \times 1.6 \mathrm{~mm}$ \\
\hline Fukuta et al., 1997 [28] & Electrostatic & - & $40 \mathrm{~nm}$ & - & $50 \mu \mathrm{m} \times 75 \mu \mathrm{m}$ \\
\hline Jaecklin et al., 1992 [32] & Electrostatic & $10 \mu \mathrm{m}$ & - & $\pm 50 \mathrm{~nm}$ & $2.2 \mathrm{~mm} \times 2.2 \mathrm{~mm}$ \\
\hline Hirano et al., 1998, $1999[5,6]$ & Electrostatic & $0.6 \mu \mathrm{m}$ & - & $\pm 50 \mathrm{~nm}$ & $1.7 \mathrm{~mm} \times 2.7 \mathrm{~mm}$ \\
\hline Soeno et al., 1999 [10] & Piezoelectric & $1 \mu \mathrm{m}$ & - & $\pm 50 \mathrm{~nm}$ & $1.7 \mathrm{~mm} \times 600 \mu \mathrm{m}$ \\
\hline Hubbard and Howell, 2004 [33] & Thermal & $2 \mu \mathrm{m}$ & - & $\pm 14 \mathrm{~nm}$ & $367 \mu \mathrm{m} \times 518 \mu \mathrm{m}$ \\
\hline Syms, 2002 [18] & Thermal & $550 \mu \mathrm{m}$ & - & - & $15 \mathrm{~mm} \times 210 \mu \mathrm{m}$ \\
\hline Guckel et al., 1992 [25] & Thermal & $130 \mu \mathrm{m}$ & - & - & $2 \mathrm{~mm} \times 16.5 \mu \mathrm{m}$ \\
\hline Park et al., 2001 [34] & Thermal & $33.4 \mu \mathrm{m}$ & - & - & $1 \mathrm{~mm} \times 1 \mathrm{~mm}$ \\
\hline Jang et al., 2002 [16] & Thermal & $30 \mu \mathrm{m}$ & - & - & $700 \mu \mathrm{m} \times 700 \mu \mathrm{m}$ \\
\hline Comtois et al., 1997 [35] & Thermal & $19.1 \mu \mathrm{m}$ & - & - & $11 \mu \mathrm{m} \times 250 \mu \mathrm{m}$ \\
\hline Jonsmann et al., 1999 [29] & Thermal & $17 \mu \mathrm{m}$ & - & - & $500 \mu \mathrm{m} \times 200 \mu \mathrm{m}$ \\
\hline Reid et al., 1996 [14] & Thermal & $16 \mu \mathrm{m}$ & - & - & $21 \mu \mathrm{m} \times 240 \mu \mathrm{m}$ \\
\hline Oliver et al., 2003 [36] & Thermal & $12 \mu \mathrm{m}$ & - & - & $324 \mu \mathrm{m} \times 15 \mu \mathrm{m}$ \\
\hline Cragun and Howell, 1999 [24] & Thermal & $12 \mu \mathrm{m}$ & - & - & $300 \mu \mathrm{m} \times 550 \mu \mathrm{m}$ \\
\hline Lott et al., 2002 [27] & Thermal & $11.7 \mu \mathrm{m}$ & - & - & $240 \mu \mathrm{m} \times 750 \mu \mathrm{m}$ \\
\hline Que et al., 2001[37] & Thermal & $5 \mu \mathrm{m}$ & - & - & $81 \mu \mathrm{m} \times 800 \mu \mathrm{m}$ \\
\hline Neagu et al., 1997 [23] & Chemical & $13 \mu \mathrm{m}$ & - & - & $2 \mathrm{~mm} \times 2 \mathrm{~mm}$ \\
\hline
\end{tabular}

Italicized values are not explicitly stated in the literature but have been estimated from the available information.

Table 2. Results of the Measurement Repeatability Tests

\begin{tabular}{cccc}
\hline Test & $\begin{array}{c}\text { Number of } \\
\text { Repetitions }\end{array}$ & $\begin{array}{c}\text { Nominal } \\
\text { Dimension }\end{array}$ & Precision Interval \\
\hline 1 & 31 & $6 \mu \mathrm{m}$ & $6.006 \mu \mathrm{m} \pm 5.6 \mathrm{~nm}$ \\
\hline 2 & 31 & $12 \mu \mathrm{m}$ & $11.985 \mu \mathrm{m} \pm 7.9 \mathrm{~nm}$ \\
\hline 3 & 41 & $6 \mu \mathrm{m}$ & $6.003 \mu \mathrm{m} \pm 4.8 \mathrm{~nm}$ \\
\hline 4 & 41 & $12 \mu \mathrm{m}$ & $11.969 \mu \mathrm{m} \pm 5.7 \mathrm{~nm}$ \\
\hline
\end{tabular}


Table 3. Electrical Inputs for the First Resolution Test

\begin{tabular}{cccc}
\hline Step & Current $(\mathbf{m A}) *$ & Voltage $(\mathbf{V})^{\dagger}$ & Power $(\mathbf{m W})^{*}$ \\
\hline 1 & 29.58 & 2.500 & 73.95 \\
\hline 2 & 29.66 & 2.508 & 74.39 \\
\hline 3 & 29.75 & 2.518 & 74.91 \\
\hline 4 & 29.66 & 2.507 & 74.36 \\
\hline 5 & 29.58 & 2.500 & 73.95 \\
\hline$* \pm 0.002 \mathrm{~mA}$ & & \\
$\dagger$ & & \\
$\pm 0.0002 \mathrm{~V}$ & & \\
$\pm 0.006 \mathrm{~mW}$ & &
\end{tabular}

Table 4. Electrical Inputs for the Second Resolution Test

\begin{tabular}{cccc}
\hline Step & Current $(\mathbf{m A}) *$ & Voltage $_{(\mathbf{V})^{\dagger}}$ & Power $(\mathbf{m W})^{*}$ \\
\hline 1 & 29.58 & 2.501 & 73.98 \\
\hline 2 & 29.75 & 2.518 & 74.91 \\
\hline 3 & 29.95 & 2.539 & 76.04 \\
\hline 4 & 29.75 & 2.518 & 74.91 \\
\hline 5 & 29.58 & 2.500 & 73.95 \\
\hline$* \pm 0.002 \mathrm{~mA}$ & & \\
$\pm 0.0002 \mathrm{~V}$ & & \\
\pm & &
\end{tabular}

Table 5. Summary of Experimental Results

\begin{tabular}{lccccc}
\hline Test Type & Test Number & Result & Displacement & Current & Voltage \\
\hline Resolution & 1 & - & $4.5 \mu \mathrm{m}$ & $30 \mathrm{~mA}$ & $2.5 \mathrm{~V}$ \\
\cline { 2 - 6 } & 2 & $170 \mathrm{~nm}$ & $4.6 \mu \mathrm{m}$ & $30 \mathrm{~mA}$ & $2.5 \mathrm{~V}$ \\
\hline Repeatability & 1 & $\pm 124 \mathrm{~nm}$ & $4.6 \mu \mathrm{m}$ & $30 \mathrm{~mA}$ & $2.5 \mathrm{~V}$ \\
\cline { 2 - 6 } & 2 & $\pm 37 \mathrm{~nm}$ & $3.7 \mu \mathrm{m}$ & $27 \mathrm{~mA}$ & $2.2 \mathrm{~V}$ \\
\hline Hysteresis & 1 & $560 \mathrm{~nm}$ or $6.6 \%$ & $8.5 \mu \mathrm{m}$ & $34 \mathrm{~mA}$ & $2.9 \mathrm{~V}$ \\
\cline { 2 - 6 } & 2 & $477 \mathrm{~nm}$ or $5.5 \%$ & $8.6 \mu \mathrm{m}$ & $34 \mathrm{~mA}$ & $2.9 \mathrm{~V}$ \\
\hline Drift & 1 & $25 \mathrm{~nm}$ over $60 \mathrm{~min}$. & $7.0 \mu \mathrm{m}$ & $33 \mathrm{~mA}$ & $2.8 \mathrm{~V}$ \\
\hline
\end{tabular}




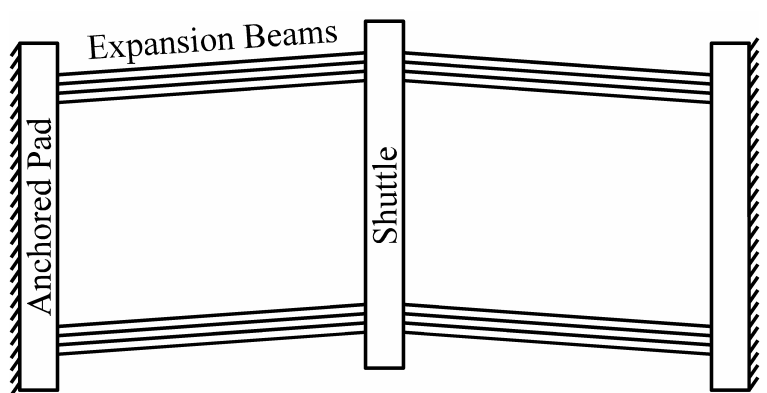

(a)

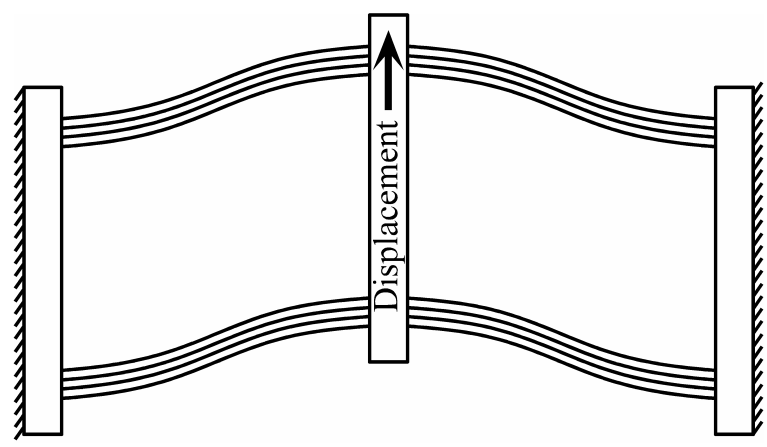

(b)

Figure 1. Schematic drawings of a TIM in (a) its undeflected position and (b) its deflected position

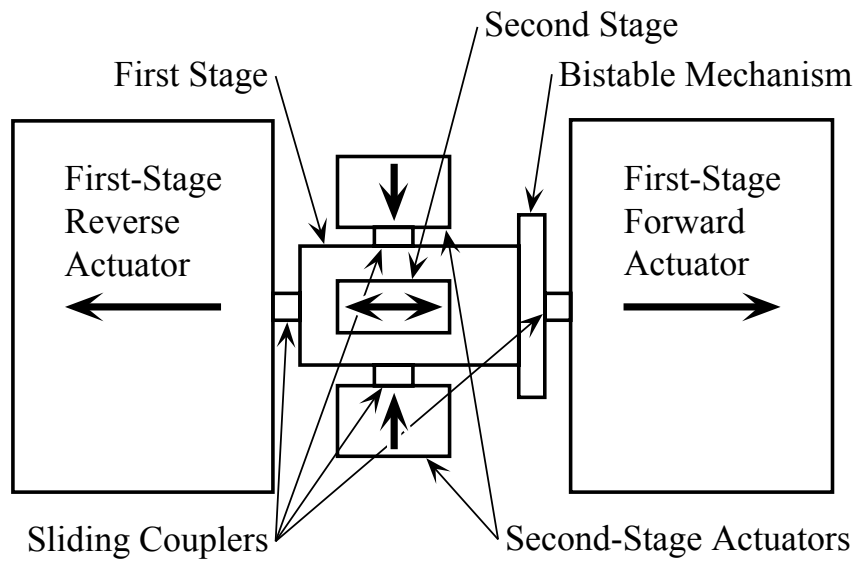

Figure 2. Layout of the nanopositioner

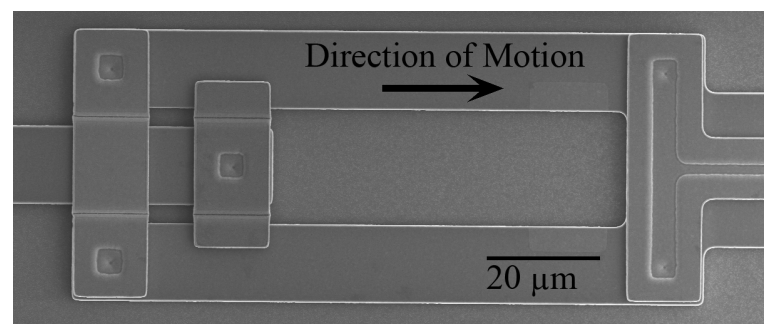

Figure 3. Sliding coupler attached to one of the first-stage actuators 


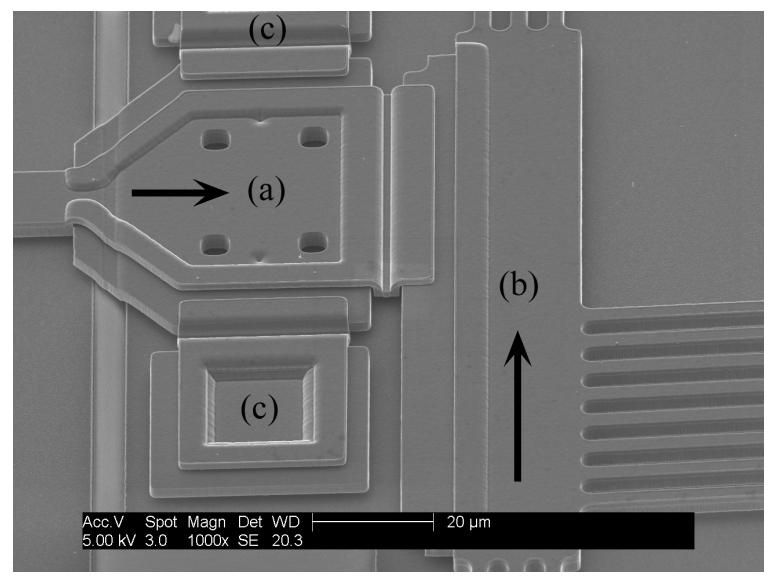

Figure 4. Sliding coupler that links (a) one of the second-stage actuators to (b) the first stage; (c) anchored guides provide support; arrows indicate the directions of motion

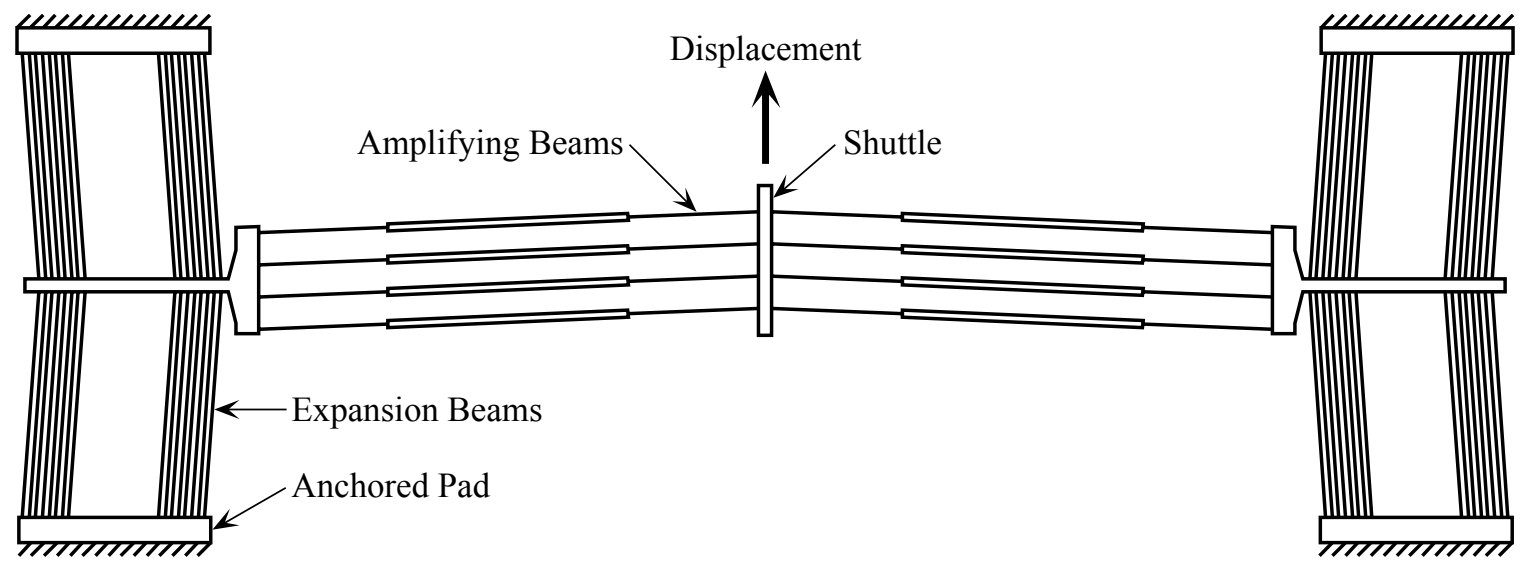

Figure 5. Schematic drawing of the ATIM

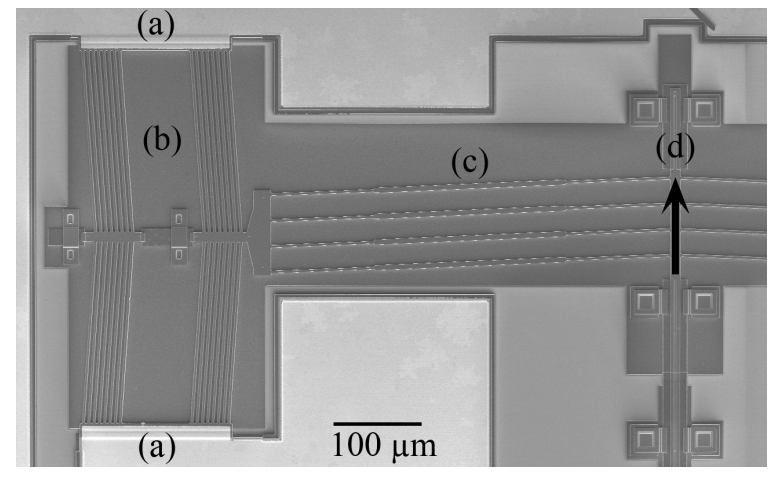

Figure 6. Scanning electron micrograph of half of an ATIM: (a) anchored pads, (b) expansion beams, (c) amplifying beams, and (d) shuttle with an arrow showing the direction of motion 


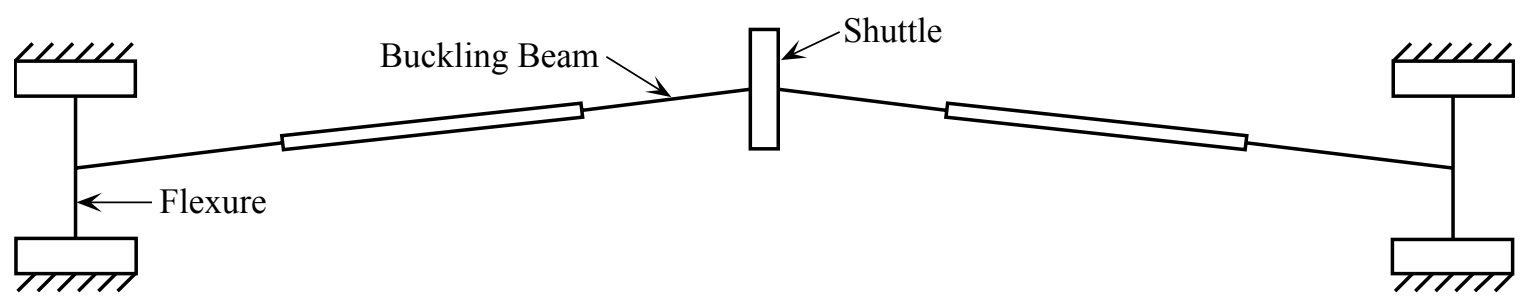

(a)

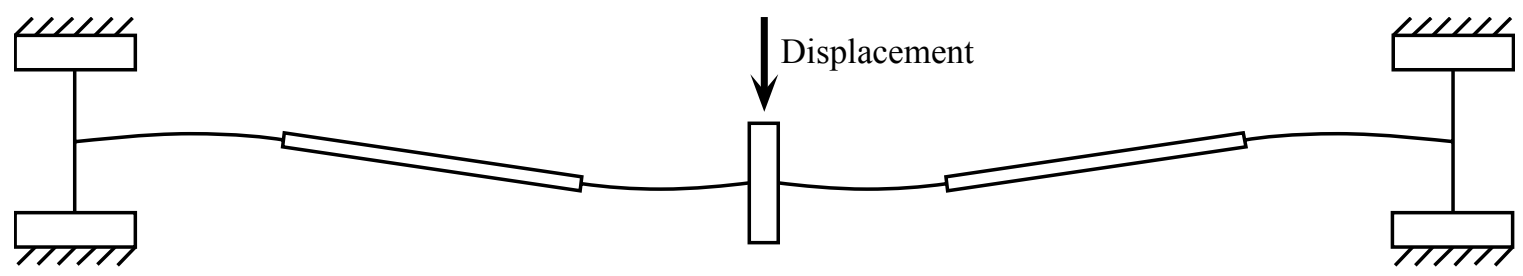

(b)

Figure 7. Illustrations of the bistable mechanism in (a) the first stable equilibrium position and (b) the second stable equilibrium position

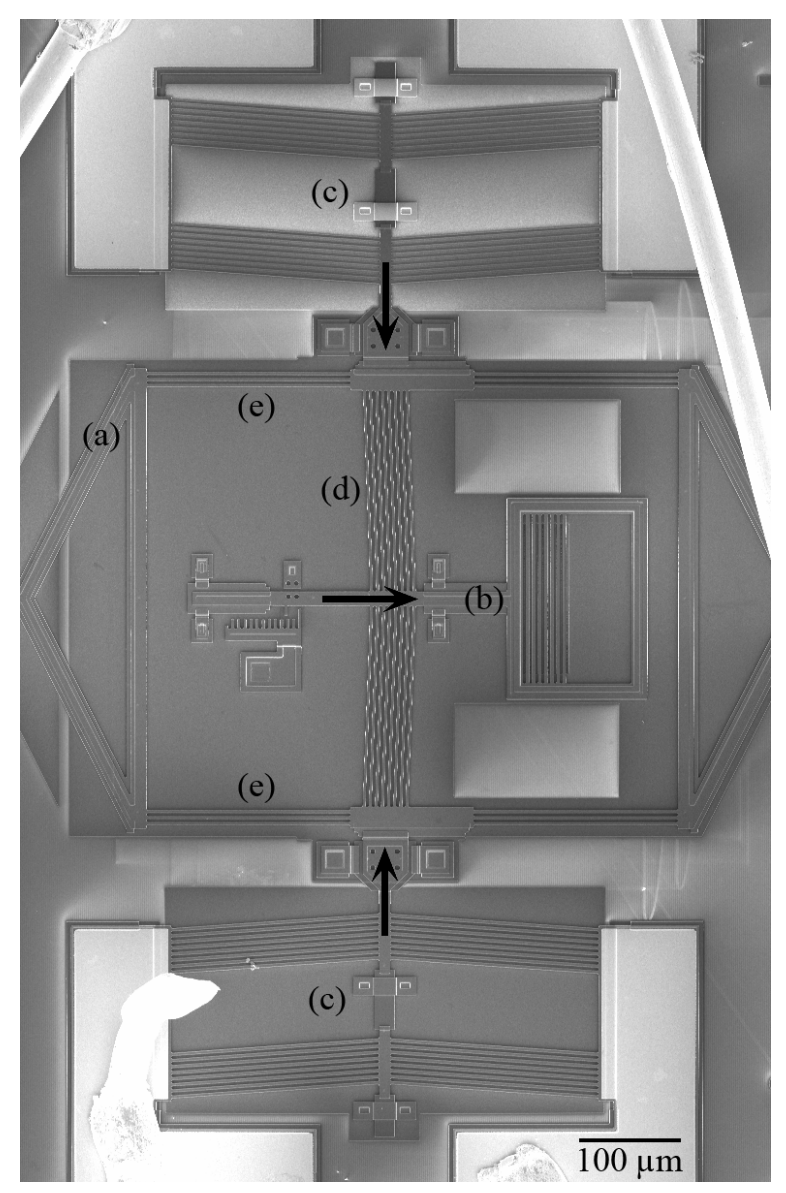

Figure 8. Integration of the two stages: (a) first-stage shuttle, (b) second-stage shuttle, (c) TIMs, (d) amplifier mechanism, and (e) flexures; arrows indicate the directions of motion 


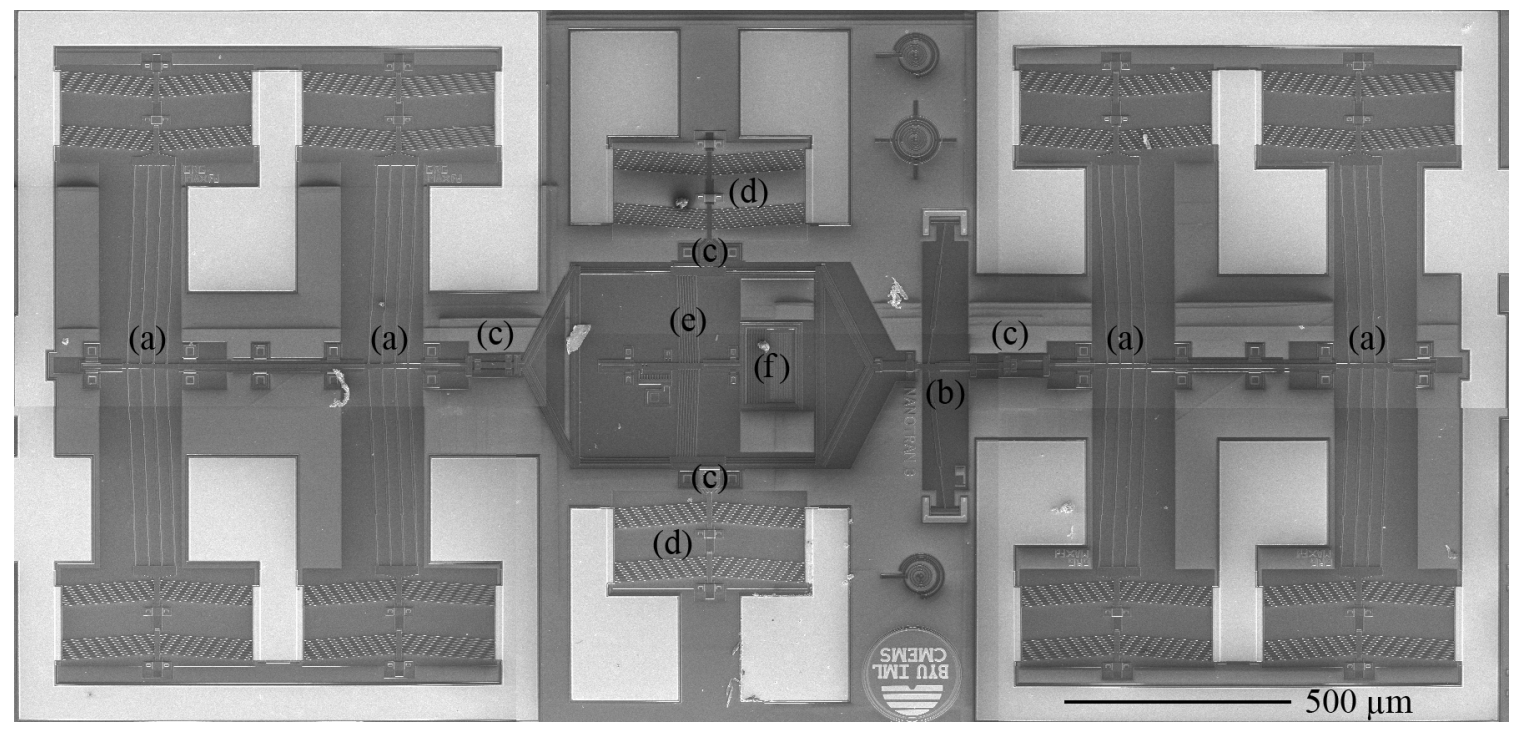

Figure 9. Components of the nanopositioner: (a) ATIMs, (b) bistable mechanism, (c) sliding couplers, (d) TIMs, (e) amplifier mechanism, and (f) gratings

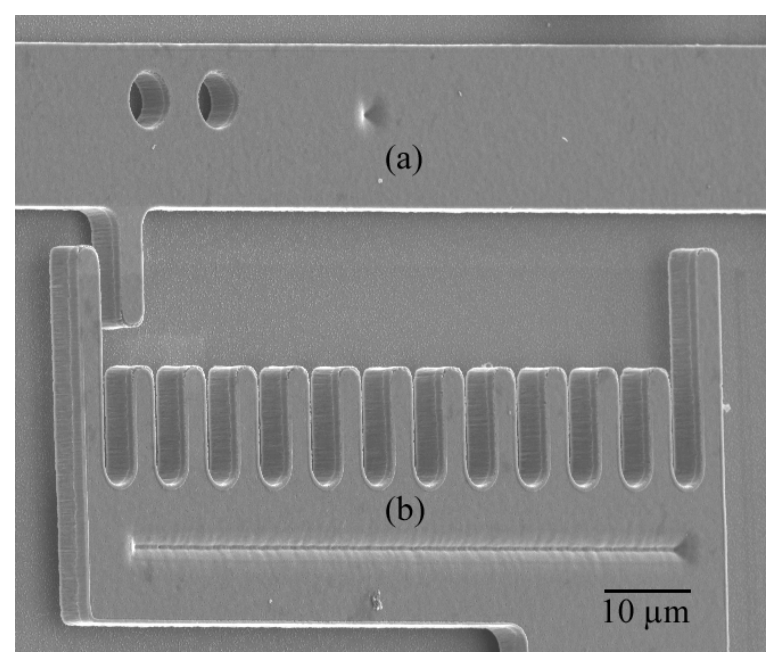

Figure 10. The position is measured by comparing (a) the second-stage shuttle to (b) a ruler attached to the substrate 


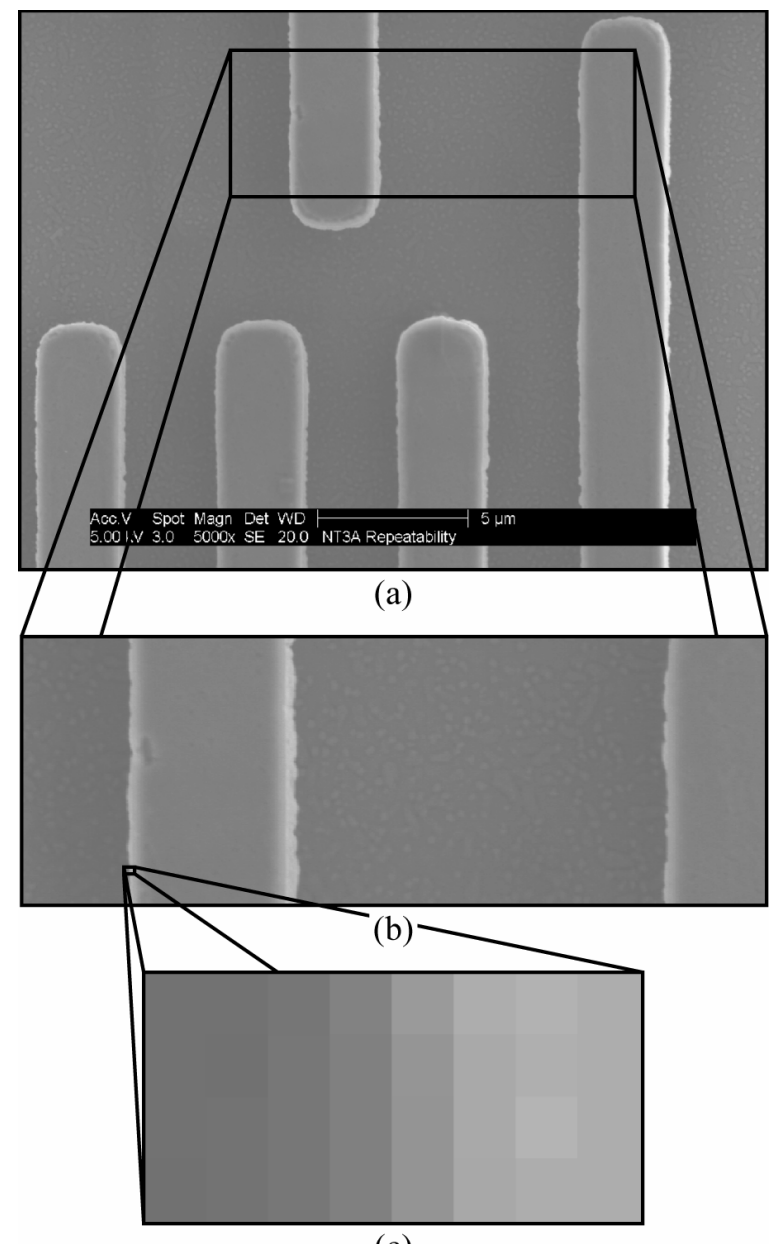

(c)

Figure 11. Sample image from a repeatability test: (a) original image, (b) cropped image, and (c) magnified view of the edge of the moving object

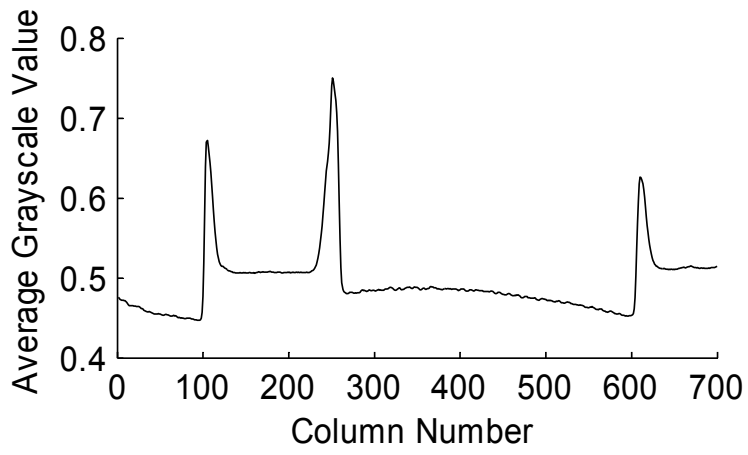

Figure 12. Grayscale profile 


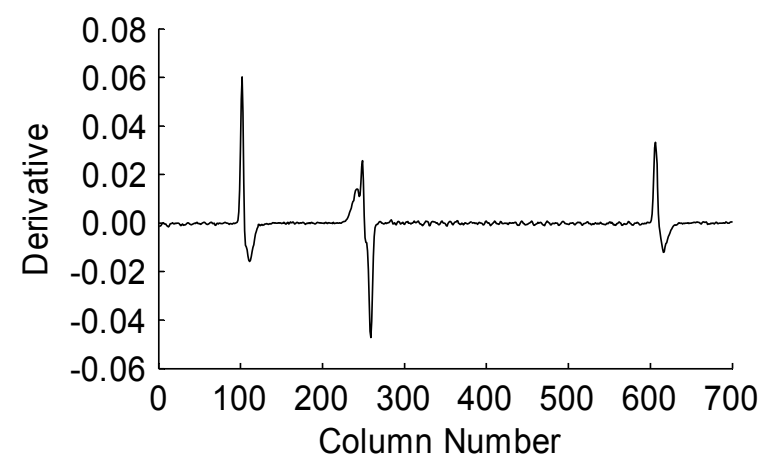

Figure 13. Derivative of the grayscale profile

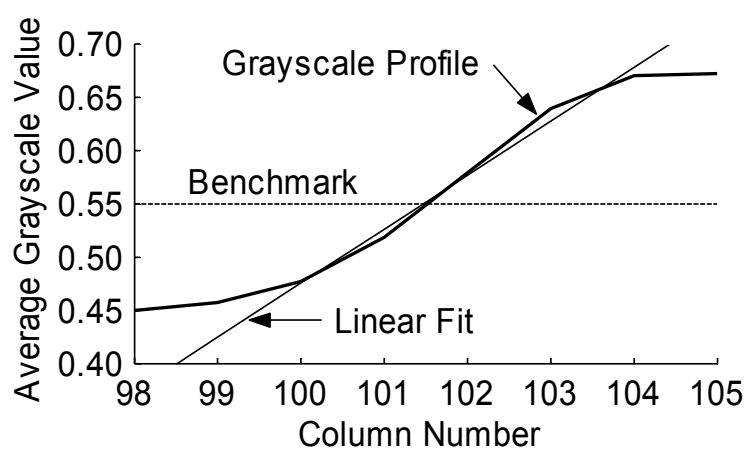

Figure 14. Location of the moving edge

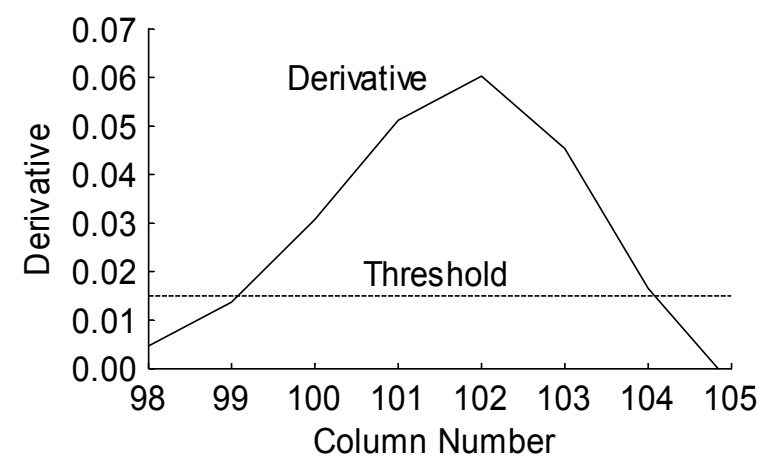

Figure 15. Identification of the moving edge 


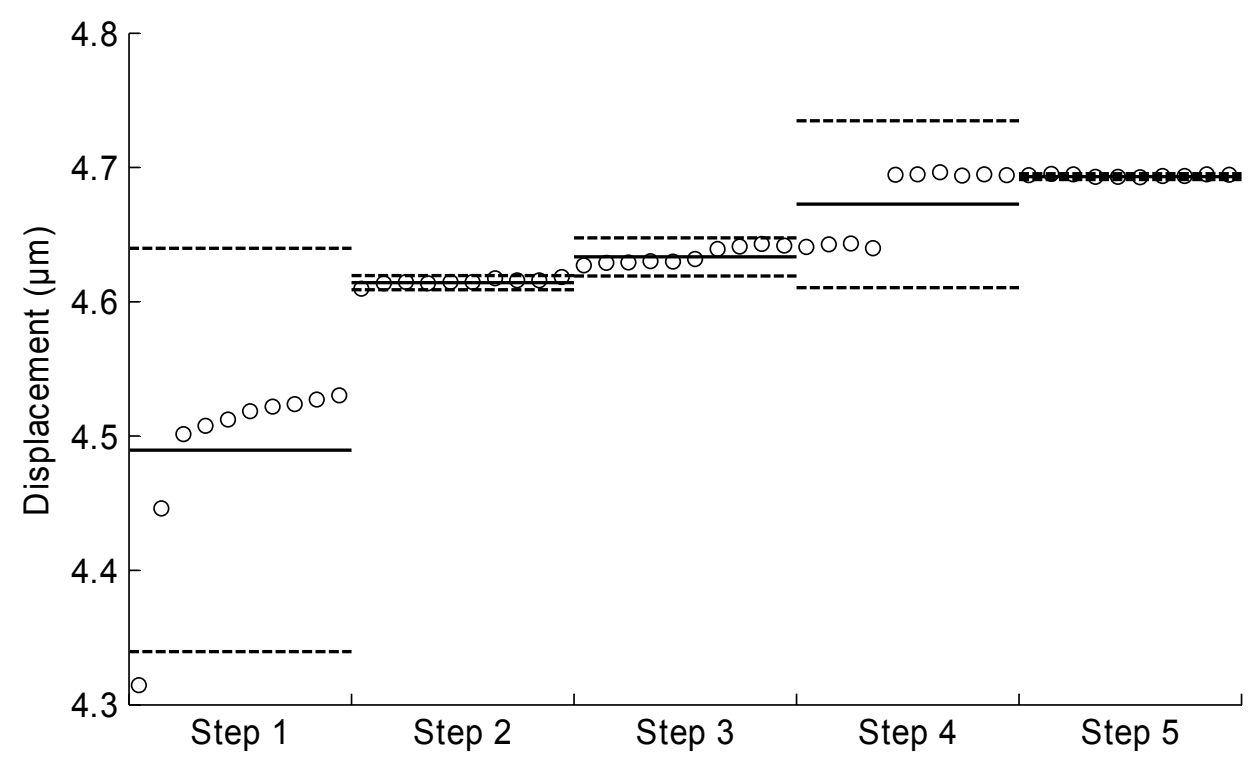

(a)

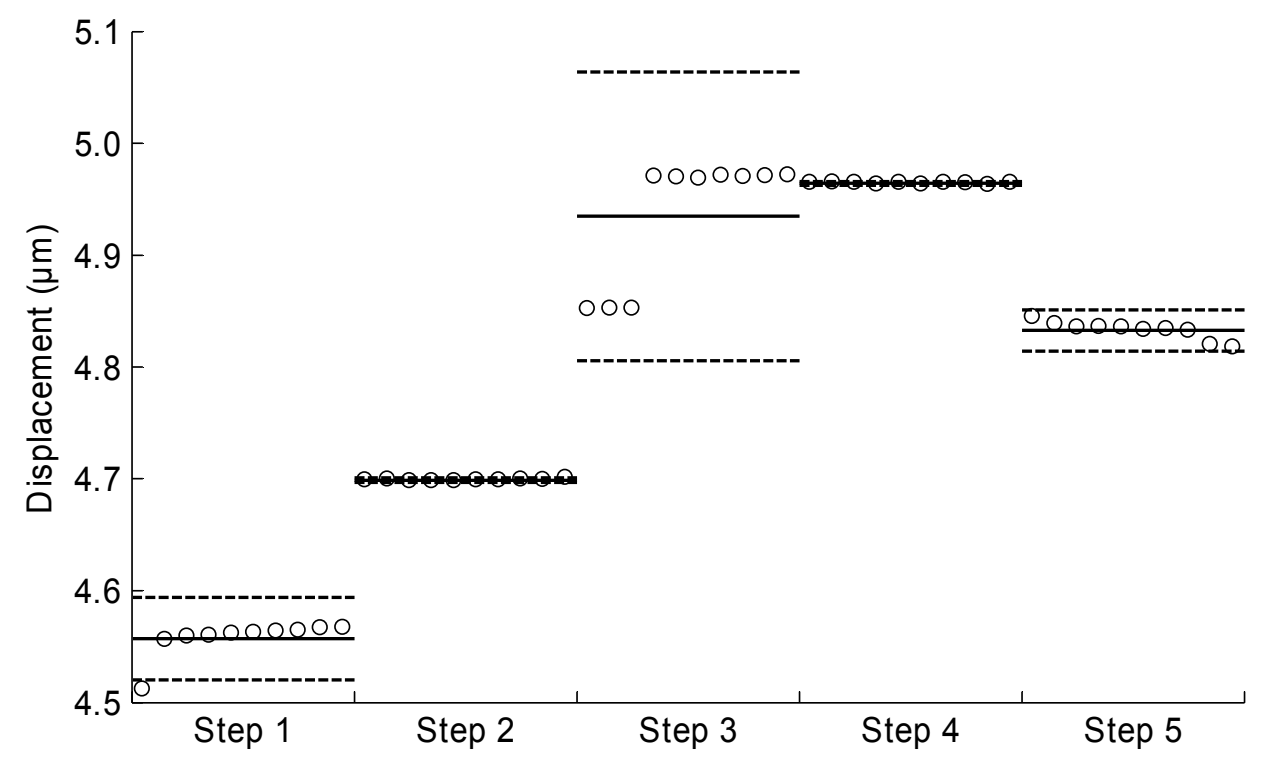

(b)

Figure 16. Results of the resolution tests with nominal current increments of (a) $0.1 \mathrm{~mA}$ and (b) $0.2 \mathrm{~mA}$ 


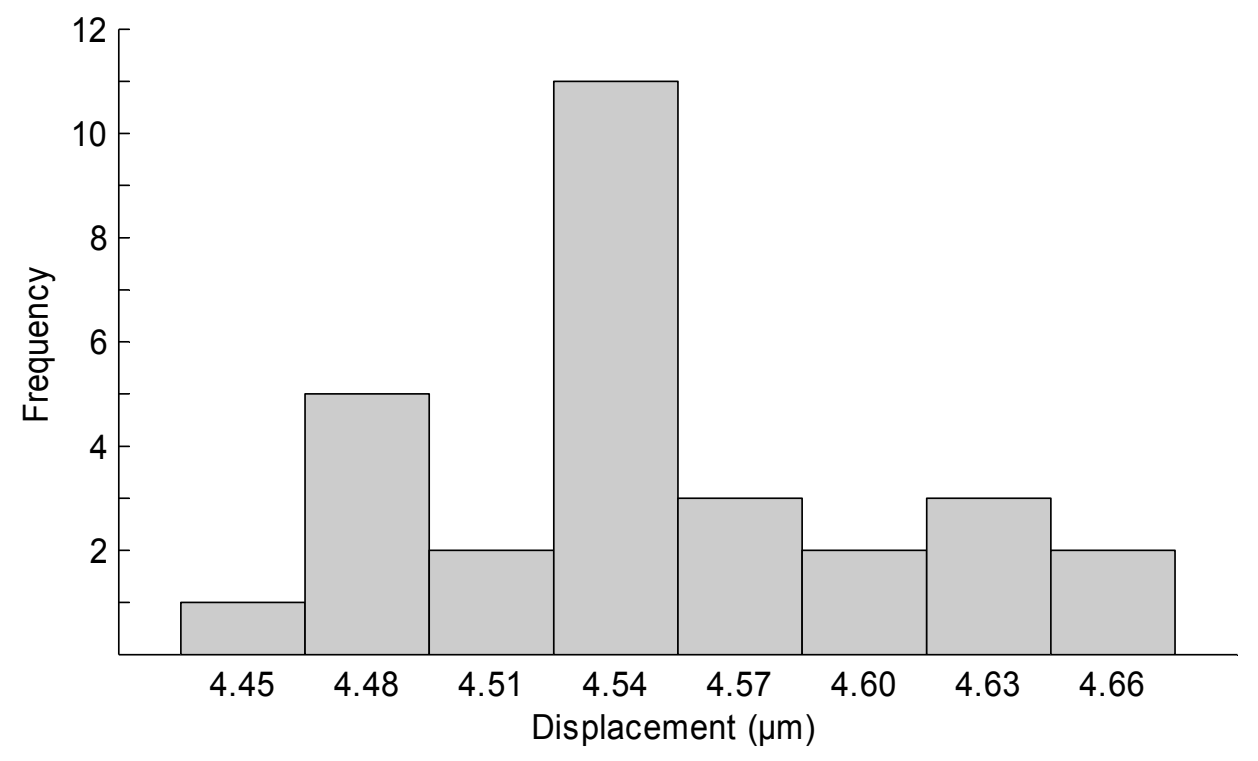

(a)

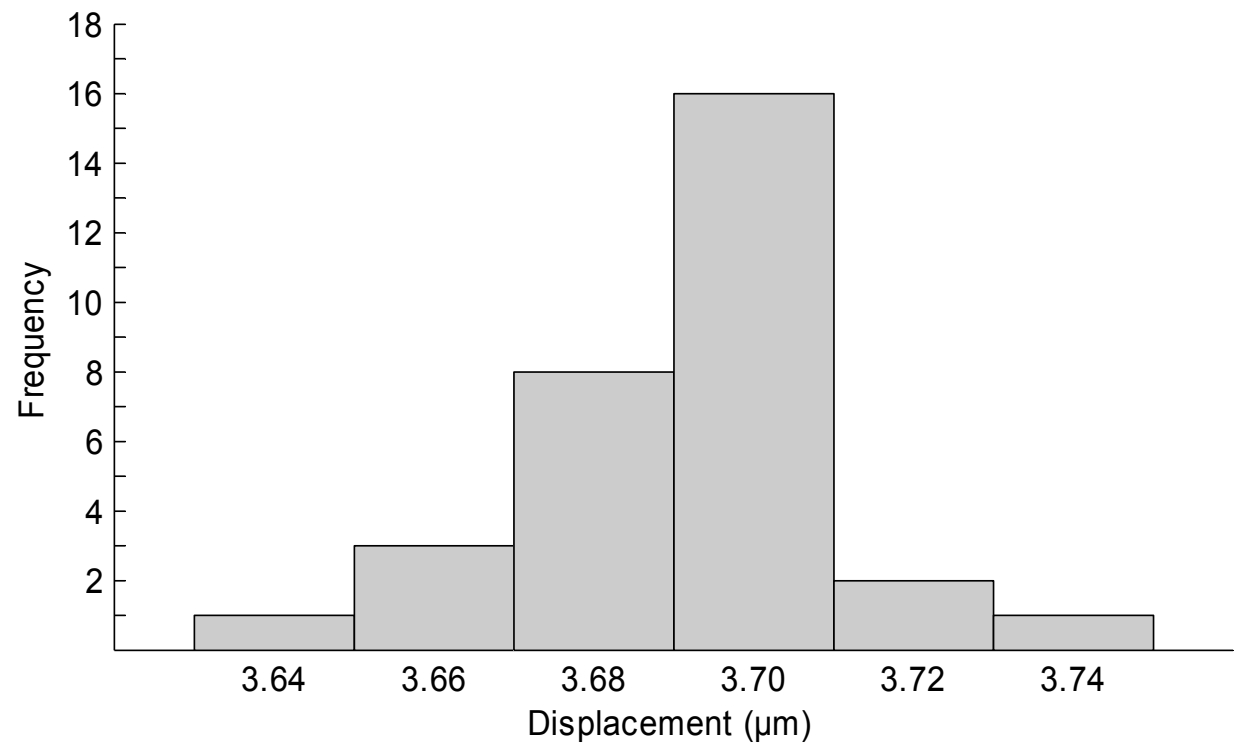

(b)

Figure 17. Histograms for the (a) first and (b) second repeatability tests 


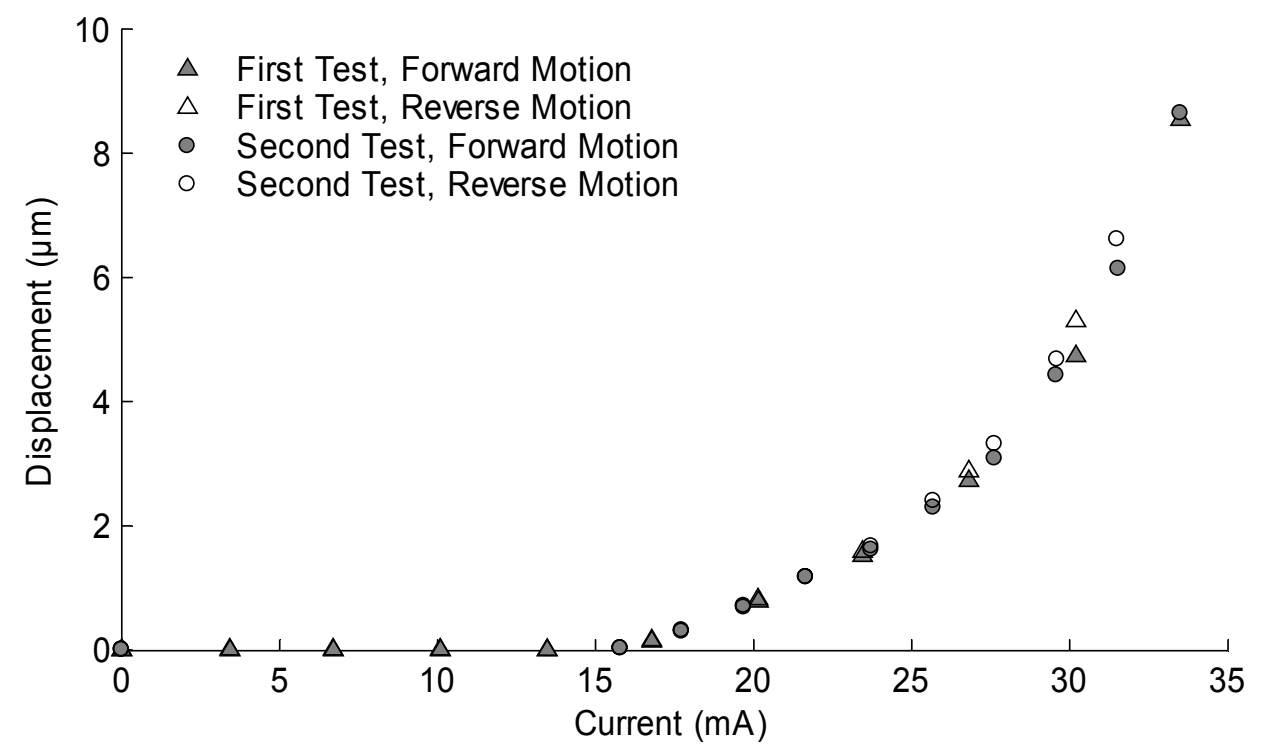

Figure 18. Results of the hysteresis tests

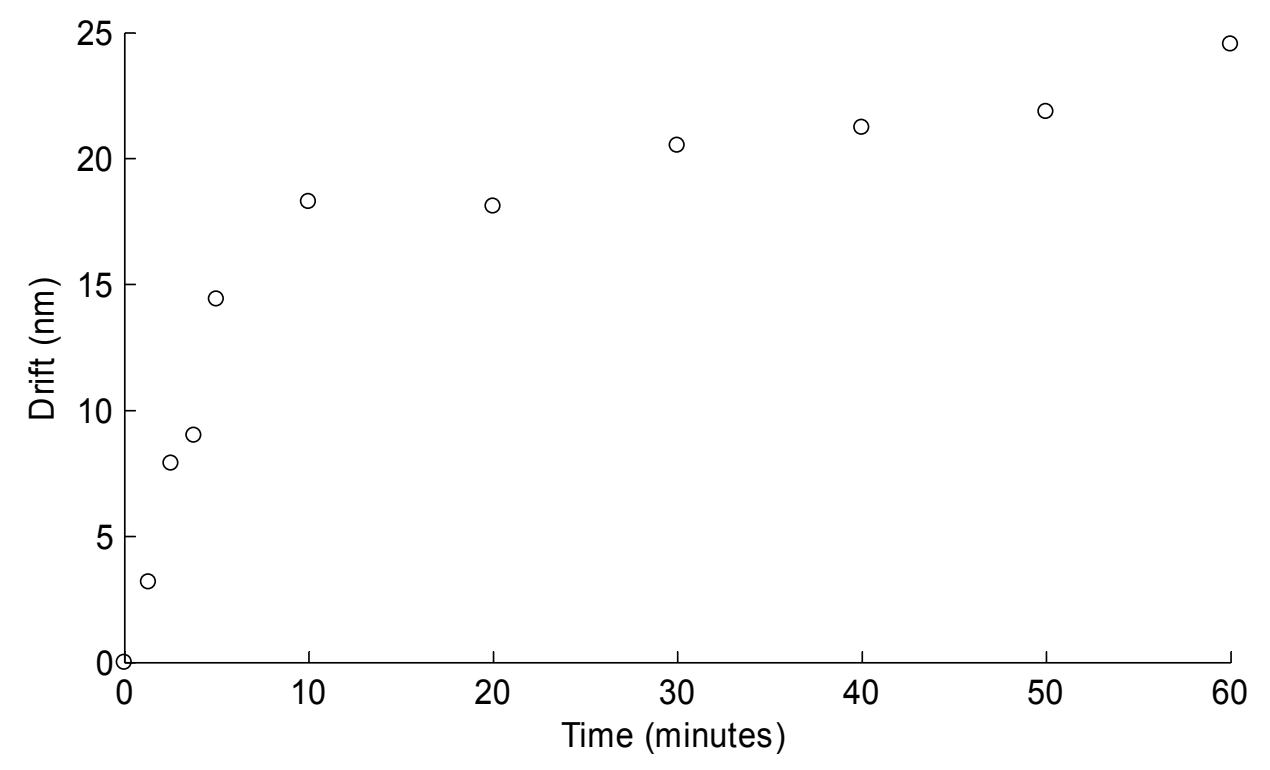

Figure 19. Thermal drift measured over a period of 60 minutes 